\section{HUGO and gene patents}

SIR - A recent News story (Nature 374, $751 ; 1995)$ attributed to the Human Genome Organisation (HUGO) the view that "patent protection of human genes is essential". This is incorrect. The original sentence from which the quoted phrase was derived reads: "In particular, we want intellectual property rights to be allocated fairly, in a manner that appropriately weighs the contributions of different parties to the total research effort, and creates necessary incentives for the ongoing development of products without interfering unduly with scientific research." This is fundamentally different from stating that patenting of gene sequences is essential. In context, the HUGO document on which your article is based stresses that if patenting is considered, the criterion should be functional utility rather than mere sequence by itself.

\section{Thomas Caskey}

(President of HUGO)

HUGO Europe,

One Park Square West,

London NW1 4L, UK

$\square$ How, within the present framework of patent law, would HUGO suggest "the contributions of different parties to the total research effort" should be accounted for? - Editor, Nature.

\section{Virology institute changes direction}

SIR - You reported (Nature 374, 299; 1995) the dismissal of Professor David Bishop from his post as director of the Natural Environment Research Council (NERC) Institute of Virology and Environmental Microbiology, Oxford, and published a comment from Bishop (Nature 374, 590; 1995).

I am writing on behalf of myself and nine colleagues*. We have been advised by the NERC that the action taken does not imply any criticism of Bishop's scientific standing. We wish to record our sympathy with Bishop and to note his scientific achievements. In the 11 years under his directorship, the institute has achieved a strong reputation, especially in virus insecticides, molecular virology and environmental microbiology. In the most recent report of the institute (1992-94) the NERC representative commented: "I find it particularly impressive that, across the whole spectrum of the Institute's activities, basic research of the highest quality is leading to potential applications of the science." The NERC Institute of Virology and Environmental Microbiology, which is a separate institution from the University of Oxford, attracts more than 55 per cent of its budget from contract research funded from the European Union, industry and government agencies other than NERC.

The matter raises two major issues. First, there is the question of the morality and legality of the abrupt dismissal. We understand that this is the subject of current proceedings. Second, there is the wider issue of the right way to evaluate science and to develop change. The mechanism of informed and transparent peer review is accepted by scientists as a fair way to evaluate research and to provide instruments for change, where necessary. Good science takes many years to build up but can be destroyed all too quickly. We hope that the NERC will find a way to fulfil its obligation to government but also to promote research which is at the forefront of knowledge in virology and that will ultimately benefit mankind by the improvement in understanding of basic science and the ability to exploit this knowledge.

\section{N. Johnson}

University of Oxford,

Laboratory of Molecular Biophysics,

South Parks Road,

OXford OX1 $3 Q U, U K$

*C. Blakemore (Laboratory of Molecular Biophysics, Oxford): G. G. Brownlee (William Dunn School of Pathology. Oxford): I. D. Campbell (Department of Biochemistry, Oxford); R.A. Dwek (Glycobiology Unit, Oxford); A. McMichael Dwek (Glycobiology Unit, Oxford); A. McMichae
(John Radcliffe Hospital, Oxford); P. C. Newell (Department of Biochemistry, Oxford): G. K. Radda (Department of Biochemistry, Oxford); K. B. M. Reld (MRC Immunochemistry Unit, Oxford): D. I. Stuart (Laboratory of Molecular Biophysics, Oxford)

\section{Neurogenetic} determinism

SIR - - The nature-nurture debate has engulfed neuroscience at least since Darwin's day. Rose's Commentary ${ }^{1}$ embodies some arguments that are overstated, offering little by way of evidence to support them.

Thus he points to setbacks in attempts to identify gene markers for neuropsychiatric disorders, asserting that "at best, the hunt for genes for these conditions may be able to identify anomalous cases in which the genetic defect is to mimic a more widespread phenotypic condition". The basis for this assertion is unclear. The early setbacks in genetic studies of schizophrenia, depression, manic depression and alcoholism appear to have stemmed largely from methodological pitfalls, not necessarily from the absence or rarity of susceptibility genes ${ }^{2}$. There are now several instructive examples. The initial genetic findings in dis-

Letters submitted for Correspondence should be typed, double-spaced, on one side of the paper only. orders such as Alzheimer's disease, diabetes mellitus and breast cancer, which resemble psychiatric disorders by way of phenotypic and genetic complexity, were not always compelling or easily replicated. With further study, there is now incontrovertible evidence of single-gene subforms for these disorders.

Rose proceeds to claim that pharmacological response rather than the clinical syndrome has been made the basis of diagnosis in psychiatry. But this claim is groundless: although response to treatment is sometimes used to 'dissect' clinical syndromes into treatment-responsive and treatment-resistant (a common and useful practice in all medicine), the principal basis for a psychiatric nosology remains behavioural phenomenology ${ }^{3}$.

Rose refers to the "almost universal conviction among biological psychiatrists that schizophrenia is a genetic disorder" and their apparent oblivion to alternative explanations. He also claims that "it is well known that with a little ingenuity any phenotypic distribution can be explained genetically, granted appropriate assumptions about partial penetrance and incomplete dominance", implying that geneticists manipulate data to 'prove' a case. But the "conviction" that schizophrenia is a genetic disorder is not universal. In fact, psychiatrists with a biological bent are all too aware that only a fraction of schizophrenic patients show high familial loading for the disorder, so that nongenetic aetiologies are at play in a substantial number of cases ${ }^{4}$. As for the allegedly manufactured 'match' between phenotypic distributions and genetic explanations, countless attempts to fit genetic models to phenotypic distributions of schizophrenia have failed to resolve the mode of inheritance 5 .

The study of brain and behaviour poses major challenges for neurogenetics. Complex phenotypes and unclear transmission patterns complicate the search for genetic underpinnings and demand full appreciation of the forces at play. The implications for society mandate caution in the interpretation of results. To ensure scientific excellence and to stave off abuse, science deserves its watchdogs. But they too should be held to high standards lest an 'anti-science' climate takes hold.

Miron Baron

Department of Medical Genetics,

New York State Psychiatric Institute and Columbia University College of Physicians and Surgeons,

New York, New York 10032, USA

1. Rose, D. Nature 373, 380-382 (1995)

2. Baron, M., Endicott, J.\& Ott, J.Br. J. Psychiat. 157. 645-655 (1990)

3. Diagnostic and Statistical Manual of Mental Disorders, Fourth Edition (American Psychiatric Association Washington, DC, 1994).

4. Gottesman, I. I \& Shields, J. Schizophrenia: The Epigenetic Puzzle (Cambridge Univ. Press, 1982). 5. Baron, M. Biol. Psychiat. 21, 1051-1066 (1986) 